\title{
A novel technique for extracting clouds base height using ground based imaging
}

\author{
E. Hirsch ${ }^{1}$, E. Agassi ${ }^{2}$, and I. Koren ${ }^{1}$ \\ ${ }^{1}$ Weizmann Institute, Department of Environmental Sciences, Rehovot, 76100, Israel \\ ${ }^{2}$ Israel Institute for Biological Research, Department of Environmental Physics, Nes-Ziona, Israel
}

Received: 13 September 2010 - Published in Atmos. Meas. Tech. Discuss.: 4 October 2010

Revised: 3 January 2011 - Accepted: 22 January 2011 - Published: 28 January 2011

\begin{abstract}
The height of a cloud in the atmospheric column is a key parameter in its characterization. Several remote sensing techniques (passive and active, either ground-based or on space-borne platforms) and in-situ measurements are routinely used in order to estimate top and base heights of clouds. In this article we present a novel method that combines thermal imaging from the ground and sounded wind profile in order to derive the cloud base height. This method is independent of cloud types, making it efficient for both low boundary layer and high clouds. In addition, using thermal imaging ensures extraction of clouds' features during daytime as well as at nighttime. The proposed technique was validated by comparison to active sounding by ceilometers (which is a standard ground based method), to lifted condensation level (LCL) calculations, and to MODIS products obtained from space. As all passive remote sensing techniques, the proposed method extracts only the height of the lowest cloud layer, thus upper cloud layers are not detected. Nevertheless, the information derived from this method can be complementary to space-borne cloud top measurements when deep-convective clouds are present. Unlike techniques such as LCL, this method is not limited to boundary layer clouds, and can extract the cloud base height at any level, as long as sufficient thermal contrast exists between the radiative temperatures of the cloud and its surrounding air parcel. Another advantage of the proposed method is its simplicity and modest power needs, making it particularly suitable for field measurements and deployment at remote locations. Our method can be further simplified for use with visible CCD or CMOS camera (although nighttime clouds will not be observed).
\end{abstract}

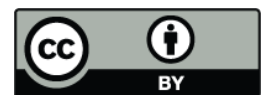

Correspondence to: E. Hirsch (eitan.hirsch@weizmann.ac.il)

\section{Introduction}

Parameterization of cloud fields in the atmosphere has crucial importance for atmospheric science (Kiehl and Trenberth, 1997) and aviation safety (Schafer et al., 2004) applications. Remote cloud sensing techniques can be characterized by the observation point - space or ground based measurements, and by the sensing method - either active (cloud/rain radar, LIDAR) or passive. In addition, cloud boundaries can be retrieved by in-situ measurements of the atmospheric profile with radiosonde. The overall cloud effects on the atmosphere and on the Earth's radiative budget depend on cloud height, thickness, and its radiative properties (IPCC, 2007). Since complex feedbacks are involved, the presence of a cloud layer can either cool the atmosphere and surface below it by absorption and reflection of the incoming shortwave solar flux, or warm it by absorption and emission of ground emitted long-wave radiation (Kiehl and Trenberth, 1997). As a result, shallow clouds which usually reflect significant amount of the received solar irradiance, have only a minor effect on the total thermal radiation emitted by the Earth, since the magnitude of their emitted radiation is comparable with a cloud free surface. On the other hand, high clouds, such as anvils (Koren et al., 2010) or cirrus, may have relatively low reflectance in the visible portion of the spectrum, and might noticeably cause warming of the atmosphere.

Profile-based cloud boundary retrieval techniques, such as LCL (Wang and Rossow, 1995; Chernykh and Eskridge, 1996), usually calculate the height at which an air parcel would reach saturation when lifted and cooled adiabatically. These techniques are considered reliable for convective clouds in well mixed boundary layers, but are less suitable for clouds forming above rugged terrain (Craven et al., 2002) and not suitable for clouds outside the boundary layer (Naud et al., 2003). 
Active sensing from space provides information regarding geometric, radiative and microphysical properties of clouds. These products are based on analyzing the backscatter signal of either LIDARs (e.g., CALIPSO; Winker et al., 2003) or Radars (CloudSat and TRMM for example; see Stephens et al., 2002 and Kummerow et al., 1998). Regarding clouds vertical extent, active sensing from space enables the extraction of the top and frequently the base heights of clouds (unless very thick, convective clouds are present). Spaceborne passive sounding, on the other hand, enables retrieval solely of cloud top heights (Platnick et al., 2003), by using multiple pairs of ratios of the measured radiance within two wavelengths in the vicinity of $\mathrm{CO}_{2}$ absorption bands. Active ground observations of clouds are routinely carried out for aviation safety. The required information in this application is usually cloud layer base heights and fractional coverage of the sky hemisphere. A common and widely used technique is analysis of the backscatter signal of a laser beam transmitted vertically from the ground (Pal et al., 1992). This technique is considered reliable and usually provides the vertical extent of the clouds as well, although the commercial instruments for this purpose (ceilometers) are usually limited by range (typically, up to $7 \mathrm{~km}$ ) due to energy constraints of the transmitter. Active sensing from the ground can be also used for retrieval of radiative and microphysical properties of clouds as well (Chiu et al., 2007, for example). Passive ground observations for extraction of cloud features are rare, although it was shown that radiance rationing near an absorption band of $\mathrm{CO}_{2}$ at $15 \mu \mathrm{m}$ enables the extraction of cloud base heights using a FTIR interferometer (Mahesh et al., 2001). Passive ground based techniques are usually used for cloud coverage measurements with a wide angle lens and a simple CCD camera (such as the Total Sky Imager; Long et al., 2001). Although this method has great advantages over active sensing in terms of cost and flexibility, it cannot provide the cloud base height, furthermore strong solar radiation scattering complicates the cloud image analysis. Using CCD cameras has an additional disadvantage: natural illumination is needed to obtain a good sky image for analysis. Employing LWIR imagers instead of CCD cameras can eliminate the last two problems and offers high sensitivity due to the thermal contrast between the clear sky and the clouds. Therefore it is most likely that IR measurements of the sky will provide high contrast images even of sparse, thin clouds, throughout the day and night. Until several years ago, LWIR cameras were expensive, bulky, and required cooling. Significant progress has been achieved in the manufacturing of low-cost, reliable, uncooled small microbolometer arrays for thermal imaging. Nevertheless, we suspect the usage of this technology for cloud field monitoring will remain limited without a complementary method to retrieve cloud base height from the sky images.

In this article we introduce a simple method that enhances the utility of ground based thermal imaging, by combining the data with the atmospheric wind velocity profile, enabling derivation of cloud base at any height regardless of their type or time of measurement. An essential part of our analysis is tracking clouds motion in a sequence of successive images. This machine vision challenge has been addressed for few decades mostly due to the availability of the geostationary meteorological satellites (such as METEOSAT and GOES). Usually, the main application of this technique is to produce cloud motion vectors that can be used in numerical weather prediction. Fujita et al. (1968) were the first to use meteorological satellite to measure large scale cloud motion. Since then, numerous methods have been suggested to extract cloud motion vectors: Schmetz et al. (1993) have used local cross correlation between three successive METEOSAT images to derive the motion vectors. Ottenebacher et al. (1997) suggested that low clouds over the ocean are better tracked by using high resolution visible imagery due to higher radiative contrast and better spatial resolution than with IR imagery. Horvath and Davies (2001) suggested using near simultaneous multi-angle satellite images to retrieve both clouds height and velocity. Moreover, Velden et al. (1997) demonstrated utilizing cloud tracking methods to derive high winds by tracking water vapors in the upper troposphere. An initial step in all of the above techniques is to determine the height of the observed cloud (Schreiner and Menzel, 2002). Most of these methods use model's input of the atmospheric temperature and humidity profile to associate between the measured radiative temperature of the cloud and its vertical position. Several key differences exist between the above space borne methods to track clouds motion and the method proposed in this paper. First of all, the methods differ by their purpose. While space borne methods consider the height of the clouds as an input and use the clouds as a tracer to the wind field, we use some external source for the wind profile and derive the cloud base height. Second, the temporal resolution of the space borne imagery is $15 \mathrm{~min}$ (Schmetz et al., 2002), while the proposed method utilizes acquisition rate of $0.1 \mathrm{~Hz}$. Third, and most important, the techniques largely differ by their sensor's instantaneous field of view (IFOV). While space borne imagers' typical IFOV is several kilometers, ground based imaging with standard IR imager benefits from an IFOV of $10-20 \mathrm{~m}$ at the top of the troposphere. Unlike in space-borne remote sensing measurements, the contribution of the lower, usually hot and humid, atmospheric layers to the radiative temperature of a cloud is relatively large. Therefore, utilizing a method that is independent of the humidity and temperature profile from the ground to the cloud is of great advantage. Moreover, there is no need for high accuracy calibration procedures, since the calibrated radiative temperature is not essential for the method's performance. This method can close important gaps in both space-borne and ground-based sounding of clouds. First, it can be used as a complementary analysis to space-borne remote sensing, especially where thick clouds are present, where their base heights cannot be assessed. Second, this method can be readily incorporated with 
CCD based sky imagers, which currently only analyze cloud coverage. This integration will result in a powerful measurement tool that will provide valuable data about cloud coverage and heights, all day and all year. Another advantage arises from the fact the proposed method does not require any preparations and is based on off-the-shelf equipment with modest power consumption, thus making it particularly suitable for a field measurement campaign or for operation at remote sites. The only required input is information about the atmospheric wind velocity profile, either measured by in-situ ground launched radio-sounding, or by future space-borne Doppler wind LIDAR (Tan and Andersson, 2005). Such wind LIDAR can provide wind profiles at relatively low temporal resolution, which can be further exploited by the proposed method. Obviously, the proposed method assumes the wind profile input represents the wind field above the sensor. Since one of the parameters that determine the boundary layer height is the roughness of the surface (Deardorff, 1972), it is possible that utilizing this method in rugged terrain, and using wind profile retrieved by radiosonde, will cause some errors in the retrieval of low boundary layer clouds.

In the next section the ensemble of our measurement equipment (mainly multi-spectral CCD and IR imager) is introduced as well as other data sources (local radio-sounding and ceilometers data). A detailed description of the proposed method is presented in Sect. 3, followed by examples of the method performance in Sect. 4. We conclude the article by summary and discussion.

\section{Data sources}

\subsection{On site measurement setup}

An on-site measurement assembly of sensors was built in order to provide continuous multispectral imaging of cloud fields. The CLOUDS SPECTATOR (SPECtral spaTiAl TempOral Resolution) measurement assembly (Fig. 1) contains the following cameras:

- D1H (Nikon, USA): RGB (color), $1324 \times 2012$ pixels CCD. Field of view (FOV): $25^{\circ} \times 37^{\circ}$.

- SENSICAM (PCO, Germany): $1000 \times 1000$ pixels, thermo-electrically cooled EMCCD with NIR filter $(780 \mathrm{~nm}-900 \mathrm{~nm})$. FOV: $35^{\circ} \times 35^{\circ}$.

- A40 (FLIR SYSTEMS, USA): $240 \times 320$ pixels, microbolometer, calibrated to effective radiant temperature, uncooled IR $(7-14 \mu \mathrm{m})$ imager. FOV: $18^{\circ} \times 24^{\circ}$.

These 3 sensors were mounted on a computerized pan and tilt head, which enables automatic measurement of cloud fields and clear sky in pre-configured tasks, at various geometrical setups (azimuth, elevation and relative angle between the observer and the sun).

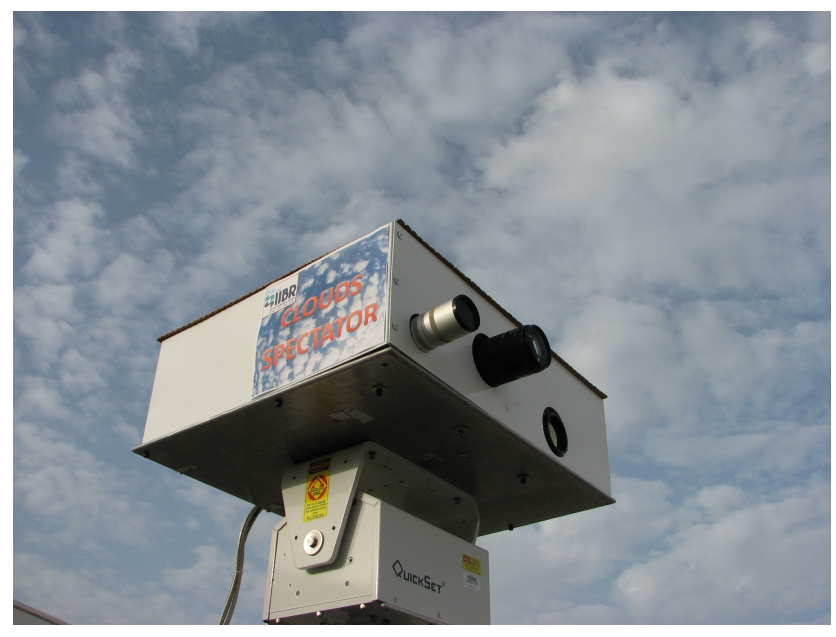

Fig. 1. CLOUDS SPECTATOR measurement assembly. It enables spatial, temporal, and multi spectral sky measurements.

The CLOUDS SPECTATOR operates on a roof of a 6 floor building, and it is in close proximity to NASA's AERONET (Holben et al., 1998) sun-photometer station (Website: "AERONET Data Display - Site: Nes_Ziona"). In addition to the SPECTATOR we conduct continuous measurements with a Net Radiometer (CNR1, Kipp \& Zonen, The Netherlands), which measures radiance of the sky hemisphere in the short-wave $(305 \mathrm{~nm}-2800 \mathrm{~nm})$ and in the longwave $(5-50 \mu \mathrm{m})$ spectral ranges. Additionally, a meteorological station constantly monitors the wind velocity (USA-1, METEK, Germany), air temperature, and relative humidity (HMP45C, Campbell Scientific INC, USA). Throughout this article, the data was obtained by the SPECTATOR in a single measurement scheme: the sensors were horizontally turned northward using a digital pitch, roll, and yaw meter (3DM, MicroStrain, USA). Afterwards, the SPECTATOR was set to an elevation angle of $90^{\circ}$, thus all clouds imaged by the cameras can be analyzed according to their direction on the compass rose. The sensors were set for continuous acquisition of sky images every $10 \mathrm{~s}$ for the IR and NIR cameras and every $60 \mathrm{~s}$ for the true-color camera. During the months of MarchMay 2010, we acquired data of 54 diurnal cycles, under various environmental and cloudiness conditions: clear skies, low cumulus clouds fields, and high cirrus clouds.

\subsection{External data sources}

Radio-sounding: our method uses the wind profile which is measured twice a day at the Beit-Dagan (which is approximately $8 \mathrm{~km}$ from our measurement site) meteorological station (Website: "Atmospheric Sounding"). These measurements are conducted at 0:00 and 12:00 GMT, and provide information about the pressure, temperature, humidity, and wind velocity profile. The use of the sounding measurement serves two purposes: derivation of the cloud base 

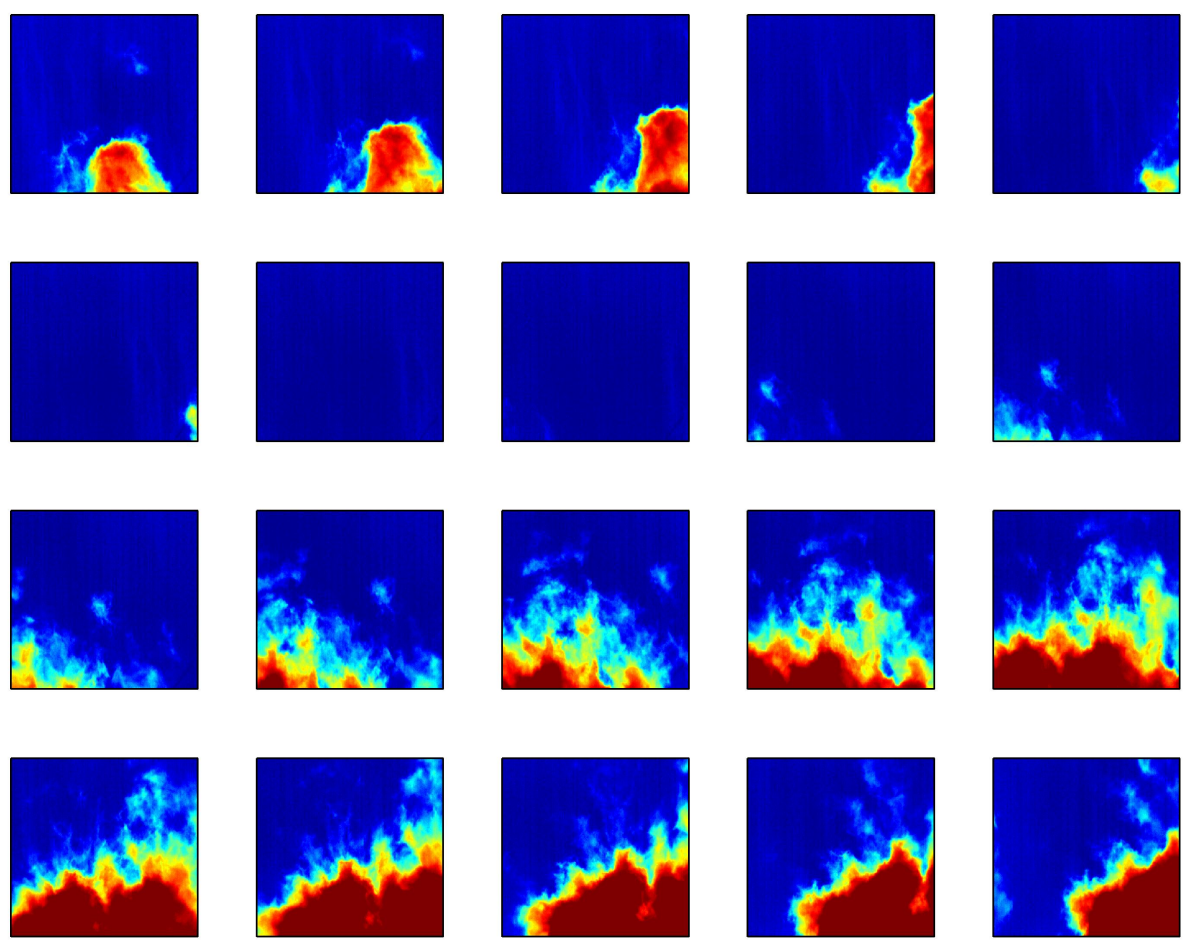

Fig. 2. A series of 20 successive IR images starting at 16 March 2010 11:31:19 UTC. Time lag between images is 10s and the color-bar scale is between $-35^{\circ} \mathrm{C}$ (blue) to $0^{\circ} \mathrm{C}$ (red).
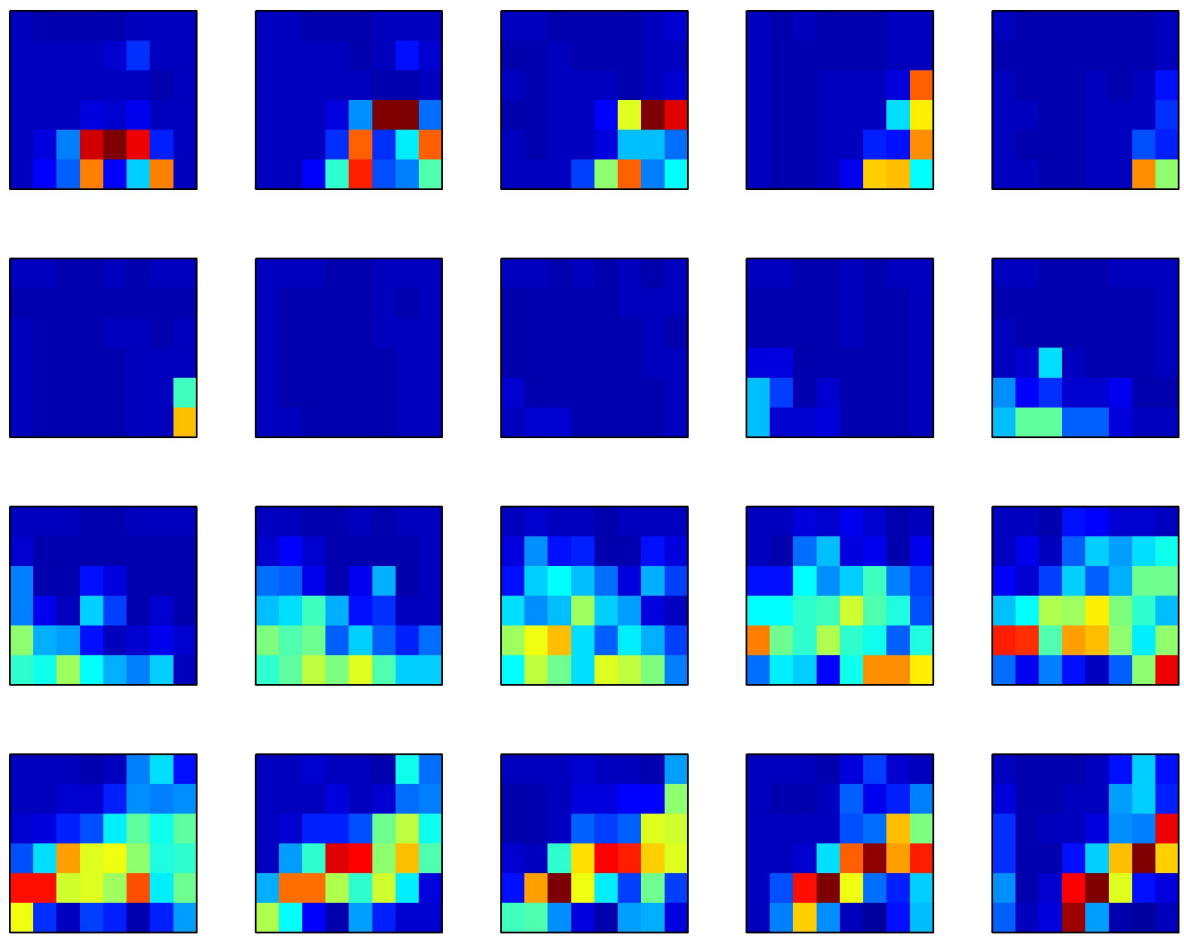

Fig. 3. Time series images of $40 \times 40$ pixels blocks of standard deviation corresponding to the thermal images shown in Fig. 2 . Images are scaled between $0{ }^{\circ} \mathrm{C}$ (blue) and $10^{\circ} \mathrm{C}$ (red). 

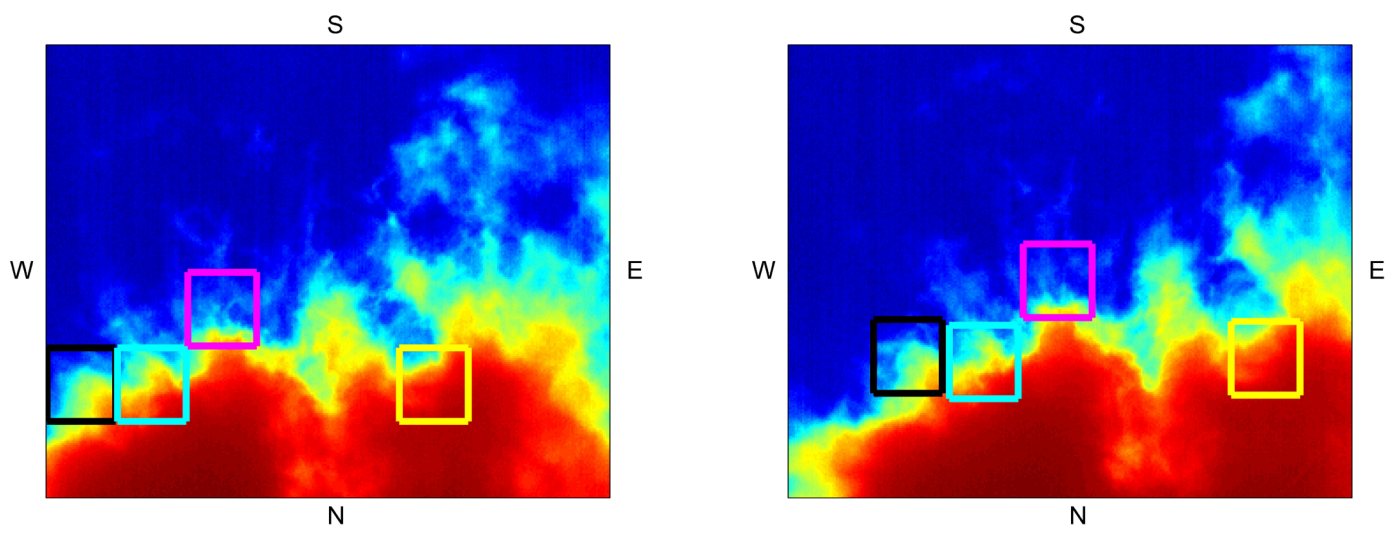

Fig. 4. Automatic detection of cloud patches movement. $40 \times 40$ pixels blocks with high standard deviation values on the left image are tracked using spatial correlation on the right image. Blocks with matching colors represent the same region. Since our sensors were turned northward prior to the image acquisition, we can mark directions on the images. This will be used later to calculate the wind direction of the air layer in which these clouds are found.

height by comparing the sounded wind velocity with our calculated wind velocity (detailed below), and validation of the cloud base height by calculating the lifted condensation level (Bolton, 1980).

Ceilometer: To validate our method's results for low cumulus clouds we use the hourly readings of the ceilometers stationed in the Ben-Gurion airport (Website: "Station Observations"), which is located approximately $10 \mathrm{~km}$ from our measurement site.

Moderate Resolution Imaging Spectroradiometer (MODIS): to validate our method's results for high cirrus clouds we use the MODIS product (Website: "LAADS Web") for cloud top pressure. This product is less suitable than active space-borne platforms (such as CloudSat or CALIPSO), but more available due to MODIS's large field of view.

\section{Extracting the clouds base heights from the measured data}

As stated in the introduction, the proposed method combines analysis of ground based thermal imaging with an atmospheric wind profile in order to extract the base heights of passing clouds. As commonly practiced in remote sensing, we assume that, as a good approximation clouds move at the same speed as the ambient body of air (Kambhamettu et al., 1996; Leese et al., 1971).

\subsection{Extraction of a single cloud base height}

Clouds form, dissipate and change continuously. In order to determine the cloud movement we use short time steps, assuming that most of the coherent differences between two sequential snapshots will be due to the cloud displacement. The cloud structure is compared for each pair of sequential snapshots, and we search for the best displacements by means of maximum correlation. As a first stage, we use the thermal images to calculate the angular velocity of the clouds. This goal is achieved by analysis of the regions in the image that pose high local contrast within a series of 20 successive thermal images (Fig. 2). These high contrast regions are tracked in the sequential image by finding the displacement which provides the maximal spatial correlation value. This procedure enables the extraction of the angular velocity of the cloud's regions, which are later used to calculate a representative angular value for the entire cloud. We use the following scheme:

- Every thermal image acquired at time $t, \operatorname{Img}^{t}$, is transformed using the following mathematical operator:

$$
\operatorname{Img} T_{(i, j)}^{t}=\sigma\left(\operatorname{Img}_{((i-1) \times 40+1: i \times 40,(j-1) \times 40+1: j \times 40)}^{t}\right)
$$

Where $\sigma(\operatorname{Img})$ is defined as the standard deviation of the radiative temperature values within the image Img. This process divides every image into blocks of $40 \times 40$ pixels. Each block is assigned with the value of the standard deviation of the radiative temperatures of the pixels that contribute to this block (Fig. 3). Thus the original $240 \times 320$ pixels images are transformed into $6 \times 8$ pixels images.

- Regions with high standard deviation values are indicators for areas with high spatial variability (usually cloud edges), which are good candidates for temporal tracking. Then, we select the top 48 blocks (5\%), out of the $960(6 \times 8 \times 20)$ blocks computed, with the highest standard deviation values as a selection criterion.

- Due to its high sensitivity to the object's shape, rather to its magnitude, we use spatial cross correlation (Jahne, 

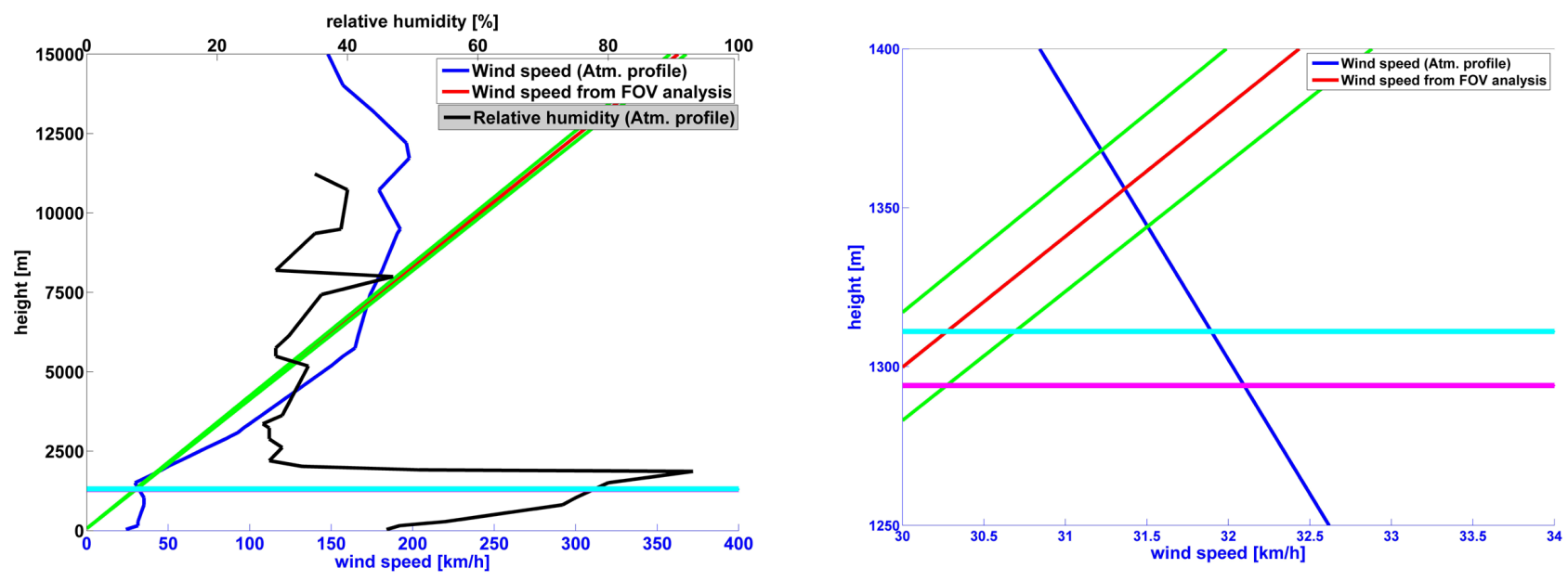

Fig. 5. Intersecting theoretical possible wind speed profile derived from FOV (field of view) analysis (red line wrapped with green error limits), with wind speed profile measured by a radiosonde in a nearby station at Beit-Dagan (blue line). The heights at which these two lines intersect mark the possible heights of the clouds layer. Left: profile range 0-15 km. Right: zooming on 1250-1400 m. The black line is the relative humidity profile (notice how the lower crossing point at $1356 \mathrm{~m}$ corresponds to a sharp increase in the RH). the magenta line is the LCL height (1294 m) as derived by the radiosonde data (Bolton, 1980). The cyan line is the cloud base height (1311 m) extracted by a nearby ceilometer (Website: "Station Observations").

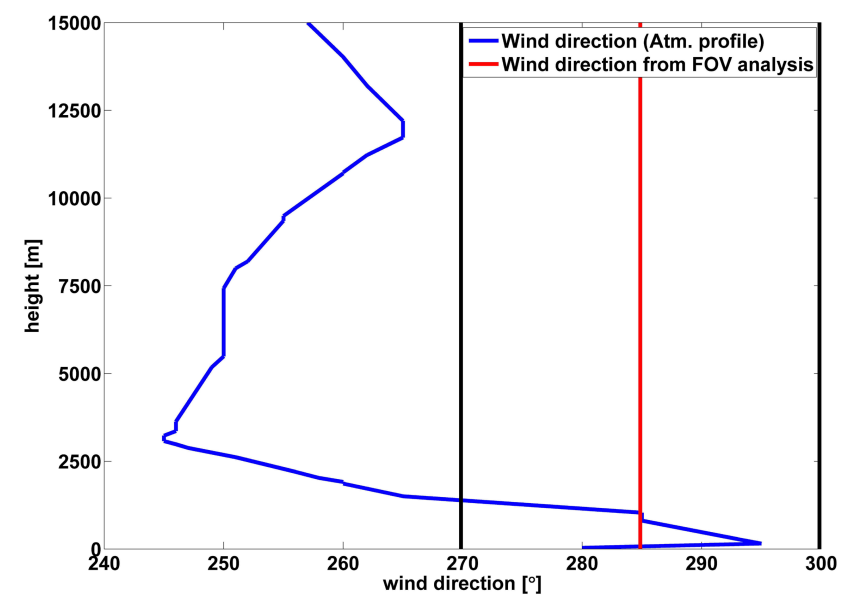

Fig. 6. Comparing measured wind direction profile (blue line) with the wind direction extracted from our FOV analysis (red line with black error values of $\pm 15^{\circ}$ ). Notice that for the lower intersection point of the wind speed profile in Fig. 5, the wind direction is within the error limit of the ground measurement, but for the higher intersection point the wind direction deviates from our calculated value, therefore the only valid cloud base height is the lower point at $1356 \mathrm{~m}$.

1997) to calculate the temporal displacement of these blocks: Let $R$ be a $40 \times 40$ pixels block in the thermal image $\operatorname{Img}^{t}$. The cross correlation matrix $\mathbf{C}_{R}$ of this block is calculated with every $40 \times 40$ region in the image $\operatorname{Img}^{t+1}$ : First, we define all possible blocks in the thermal image $\operatorname{Img}^{t+1}$ : $\forall i, j: R_{(i, j)}^{t+1}=\operatorname{Img}^{t+1}(i: i+39, j: j+39)$

Second, we build the matrix $\mathbf{C}_{R}$ by calculating the cross-correlation values of the original block $R$ with every possible block

$$
\begin{aligned}
\mathbf{C}_{R}(i, j)= & \frac{1}{40 \times 40} \times<\frac{R-\bar{R}}{\sigma(R)}> \\
& <\frac{R_{(i, j)}^{t+1}-\overline{R_{(i, j)}^{t+1}}}{\sigma\left(R_{(i, j)}^{t+1}\right)}>
\end{aligned}
$$

If the maximal value of $\mathbf{C}_{R}$ exceeds an empirically predefined threshold (0.95), we consider its spatial coordinates $\left(i_{\max }, j_{\max }\right)$, as the horizontal displacement in the image plane $D_{\mathrm{h}}=j_{\max }-j$ (pixels), and the vertical displacement $D_{\mathrm{v}}=i_{\max }-i$ (pixels). Typical results of this process are illustrated in Fig. 4.

- Since the time lag $(\Delta t)$ between the images is constant, and the IFOV (Instantaneous Field Of View) of the camera is known, the angular speed of the block (that corresponds to the cloud edge angular speed) in terms of $\mathrm{mrad} / \mathrm{s}$, is readily derived:

$$
\omega_{\mathrm{h}}^{R}=\frac{D_{\mathrm{h}} \times \text { ifov }}{\Delta t} ; \quad \omega_{\mathrm{v}}^{R}=\frac{D_{\mathrm{v}} \times \text { ifov }}{\Delta t}
$$



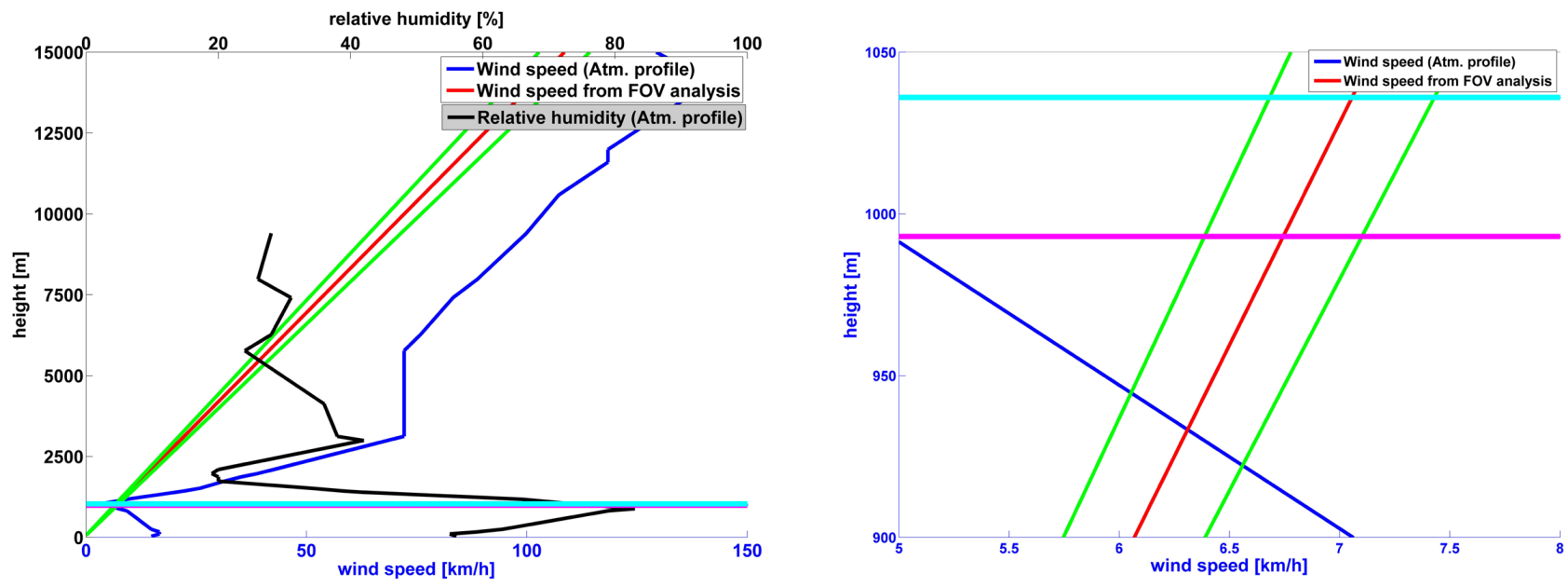

Fig. 7. Intersecting theoretical possible wind speed profile derived from FOV (field of view) analysis (red line wrapped with green error limits), with wind speed profile measured by a radiosonde in a nearby station at Beit-Dagan (blue line). The heights at which these two lines intersect mark the possible heights of the clouds layer. Left: profile range $0-15 \mathrm{~km}$. Right: zooming on $900-1050 \mathrm{~m}$. The black line is the relative humidity profile (notice how the intersection point at $934 \mathrm{~m}$ corresponds to a sharp increase in the $\mathrm{RH}$ ). the magenta line is the LCL height $(993 \mathrm{~m})$ as derived by the radiosonde data (Bolton, 1980). The cyan line is the cloud base height (1036 $\mathrm{m})$ extracted by a nearby ceilometer (Website: "Station Observations").

- In order to eliminate extreme values which originate from local failure to find a correlative block (either because the cloud segment was spatially modified or because it was no longer present in the field of view), the obtained horizontal and vertical angular speeds of the clouds $\left(\omega_{\mathrm{h}}, \omega_{\mathrm{v}}\right)$ are taken to be the median value of all calculated angular speeds.

- The planar angular speed is taken as the root of sum of squares of the horizontal and vertical angular speeds:

$\omega=\sqrt{\omega_{\mathrm{h}}^{2}+\omega_{\mathrm{v}}^{2}}$

- As mentioned above, turning our sensors northward, prior to the image acquisition, ensures that the wind direction of the air layer in which the cloud propagates is simply derived from the horizontal and vertical planar angular speeds.

Since $V=h \omega$, where $V$ is the tangential speed and $h$ is the distance between the observer and the cloud layer (cloud base height), we can derive a possible planar wind speed profile (ranging from the camera up to $15 \mathrm{~km}$ ) based on the calculated angular speed $\omega$. This hypothesized profile is then compared to the radiosonde wind velocity profile measured in Beit-Dagan (Website: "Atmospheric Sounding"). The heights $h_{p}$ at which these two lines intersect are considered an estimate of clouds' base heights (Fig. 5). Further verification is achieved by comparing the wind direction values at the possible heights to the calculated wind direction (Fig. 6). If the sounded wind direction falls within $\pm 15^{\circ}$ of the calculated value, we consider the height $h_{p(i)}$ as a valid cloud base

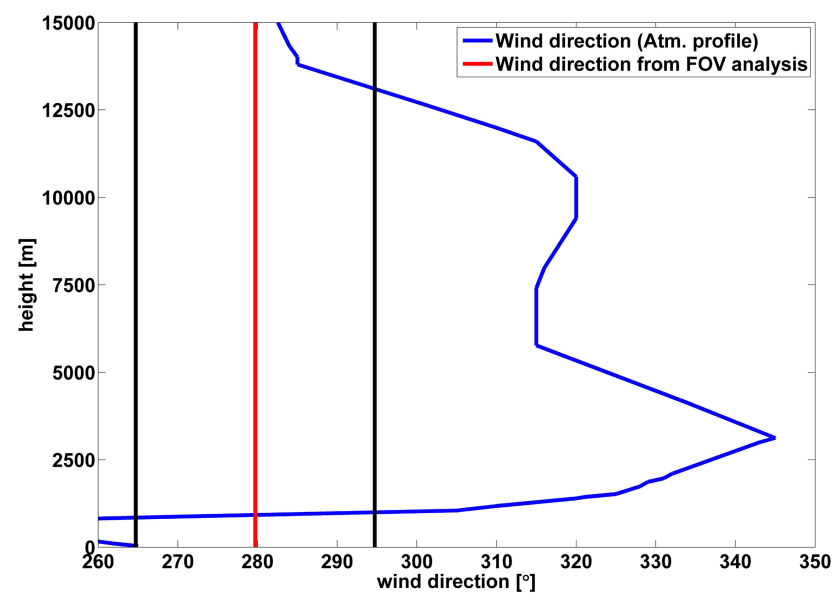

Fig. 8. Wind direction profile as measured by a radiosonde. The calculated wind direction in the cloud layer according to the FOV analysis is $280^{\circ} \pm 15^{\circ}$.

height. Naturally, there is no guarantee for the utility of the proposed method, since it depends on the specific wind velocity profile. Therefore, ambiguous results are occasionally produced, as multiple heights are obtained.

As in all retrieval techniques, the proposed analysis is subject to some possible measurement errors. We assume the error in deriving clouds motion is not higher than half a pixel in every dimension (IFOV/2 $=0.65 \mathrm{mrad}$ ). Naturally, the tangential magnitude of this error depends on the distance to the cloud as illustrated by the green error lines in Fig. 5. The result of this uncertainty in the angular velocity causes an 

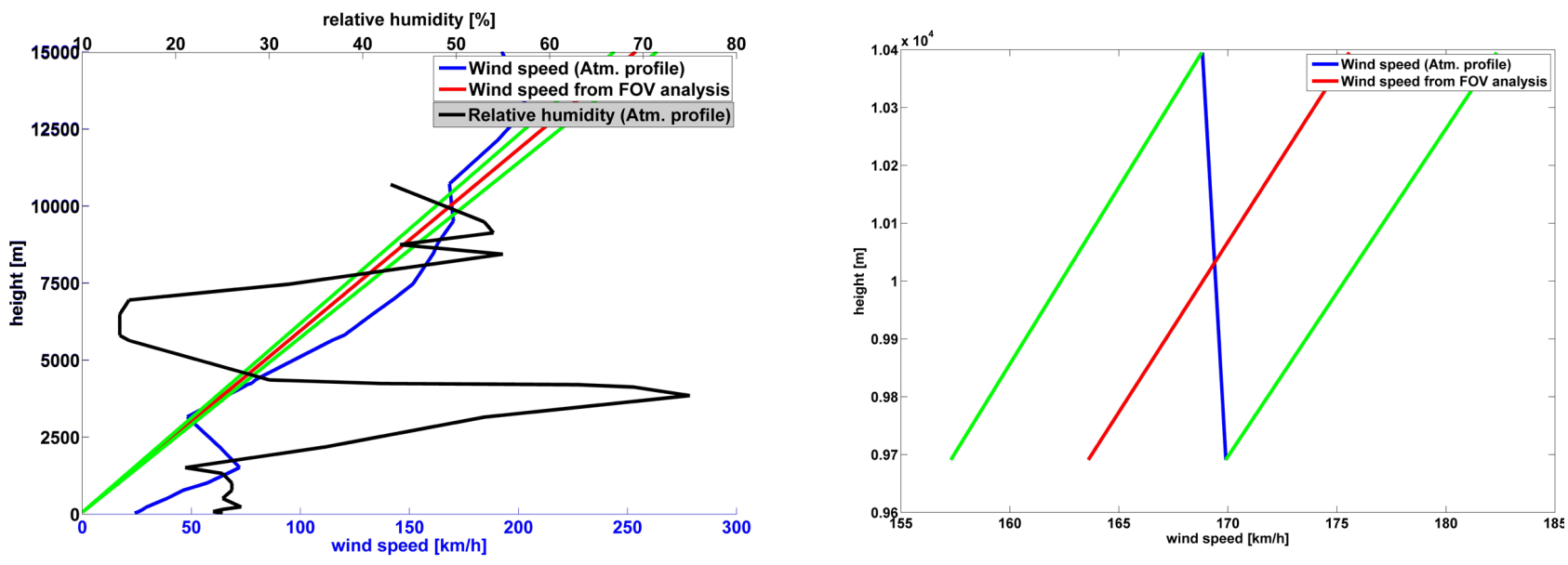

Fig. 9. Left: crossing measured wind velocity (blue line) with hypothesized possible wind velocities from FOV analysis (red line with green error lines). Notice the crossing points correspond to a high humidity layer (black line). Right: Enlargement on the top crossing point.

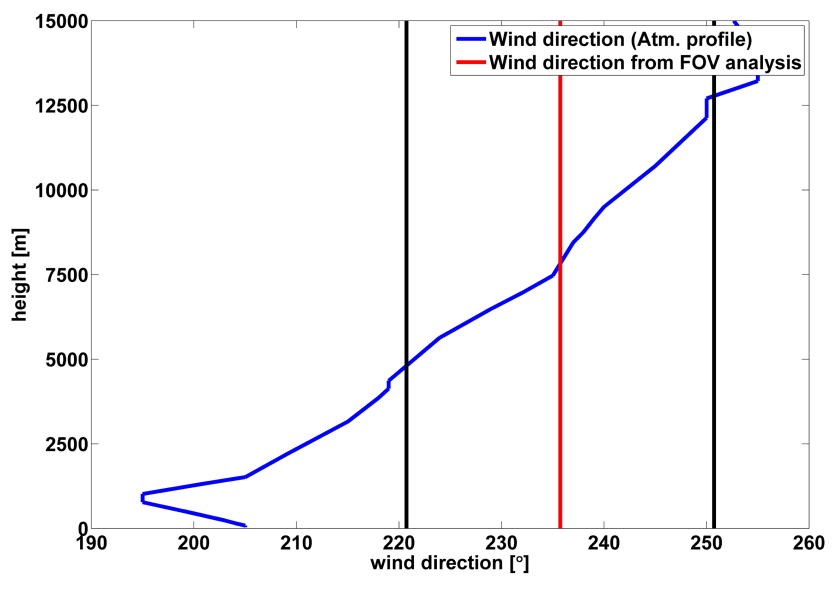

Fig. 10. Wind direction profile as measured by a radiosonde. The calculated wind direction in the cloud layer is $236^{\circ} \pm 15^{\circ}$.

uncertainty of several tens of meters for low clouds and up to several hundred meters for high clouds. Another possible error might arise in determining the direction of the clouds movement, either from imperfect position of the SPECTATOR board with regard to the north, or from imperfect alignment of the IR camera within the body of the SPECTATOR itself. To encapsulate these errors we allow margins of $\pm 15^{\circ}$ in the wind direction retrieval. As pointed above, the proposed method uses an external source for the wind profile. The accuracy of this profile can be a source of errors in the produced output of the method. In the particular example presented in Fig. 5, and error of 5\% in the provided wind speed profile causes an error of approximately $50 \mathrm{~m}$ in the cloud base height.

\subsection{Continuous operation of the retrieval method}

When operating the proposed method during a long time series it is expected that some results will be invalid. These false readings might be the result of local wind perturbation, imperfect representation of the wind profile above the sensor or even noisy data. In order to filter these false readings, we consider a reading to be valid only if it passes the following criteria: if the last 10 successive readings yielded at least 3 clouds base heights with temporal standard deviation less than $50 \mathrm{~m}$. In addition, cloud base heights above $15 \mathrm{~km}$ are rejected as they are not reasonable solution within the troposphere. This kind of temporal analysis enables to utilize the method on long time series as demonstrated in the following Sect. 4.4.

\section{Method performance}

In this section we present examples of our method's capabilities in extracting clouds base heights of several different cloud types: low cumulus, free atmosphere and high cirrus clouds. As validation to the method's readings we will use several techniques: for the low cumulus clouds we will compare to Ben-Gurion ceilometer (Website: "Station Observations") and to LCL calculation (Bolton, 1980). For the free atmosphere clouds we will compare to the ceilometer reading, and as for the cirrus clouds, we will use the MODIS clouds top pressure product (Website: "LAADS Web") since the ceilometer's maximum observation is at $\sim 7.5 \mathrm{~km}$. In addition to the above case studies we will provide several examples for the continuous operation of the proposed method, under various clouds fields, including multilayered cumulus and cirrus clouds fields at night. 

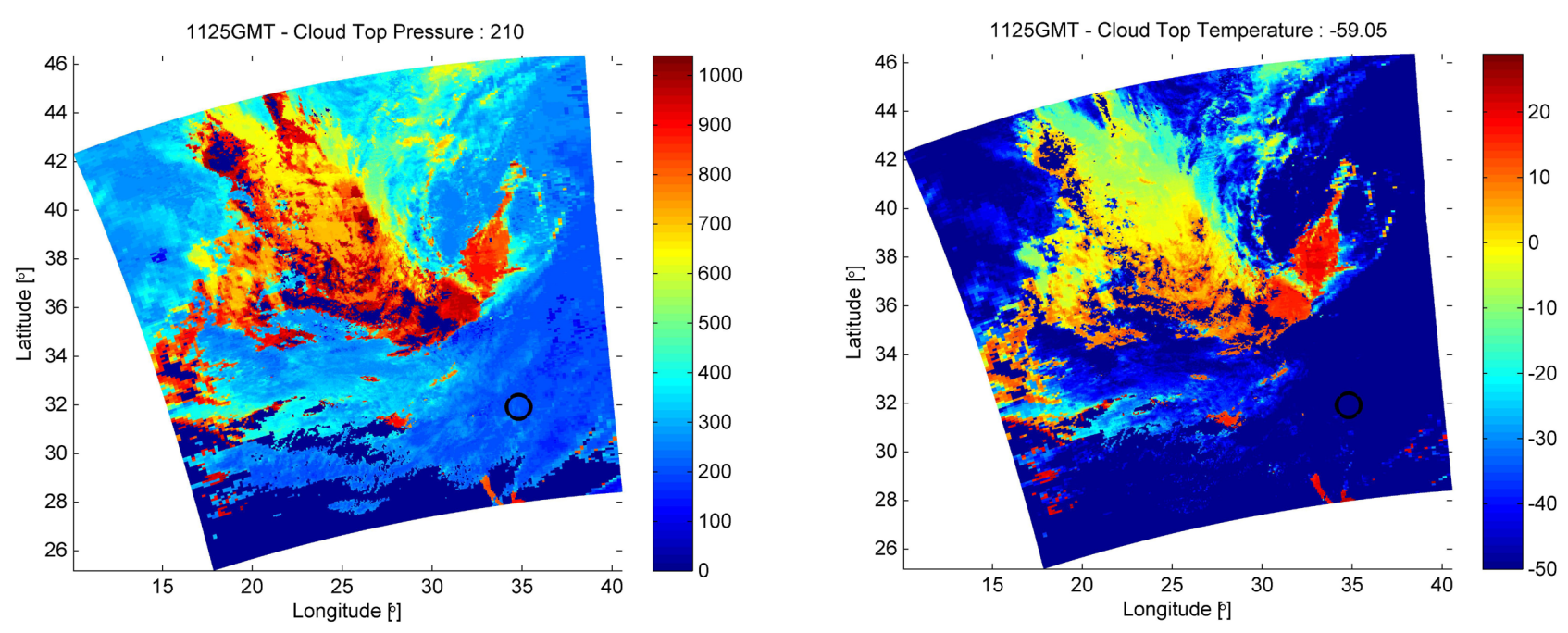

Fig. 11. MODIS cloud top pressure $(210 \mathrm{hPa})$ and temperature $\left(-59.05^{\circ} \mathrm{C}\right)$ products. The SPECTATOR location is marked with a black circle at $\left(34.79^{\circ} \mathrm{E}, 31.92^{\circ} \mathrm{N}\right)$.

\subsection{Low cumulus clouds at daytime}

Figures 7 and 8 present the analysis of thermal images that were acquired by the SPECTATOR on 4 March 2010 at 11:05 GMT. Intersecting wind speeds clearly indicate the cloud base is at $934 \mathrm{~m}$ (Fig. 7), corresponding to a high humidity layer. The estimated cloud base height is further verified by the wind direction analysis (Fig. 8); this indicates westerly wind of $280^{\circ}$ according to our FOV analysis while the measured wind direction at this height is $282^{\circ}$, well within our predefined error margins. The measured height deviates $9.8 \%$ from the ceilometer reading $(1036 \mathrm{~m})$ and $5.9 \%$ from the LCL calculation $(993 \mathrm{~m})$.

\subsection{High cirrus clouds at daytime}

Figures 9 and 10 present the analysis of thermal images that were acquired by the SPECTATOR on 9 March 2010 at 11:25 GMT. Intersecting wind speeds indicate 2 possible cloud base heights: $3600 \mathrm{~m}$ and $10020 \mathrm{~m}$ (Fig. 9), both corresponding to a high relative humidity layer. Using the wind direction profile, the lower layer is ruled out (Fig. 10), since the wind direction at this height is outside the wind direction limits. Therefore the only valid base height is $10020 \mathrm{~m}$ as verified by the wind direction profile. Since high cirrus clouds exceed the range of ceilometers, we can validate our method only by using MODIS products (Fig. 11). The retrieved data indicates cloud top pressure of $210 \mathrm{hPa}$ with a measurement error of $\pm 50 \mathrm{hPa}$ (Platnick et al., 2003). Comparing these values to the atmospheric profile (Fig. 12) at the time of the measurement, we find that, according to MODIS, the cloud top height is in the range of $10460 \mathrm{~m}-13470 \mathrm{~m}$.

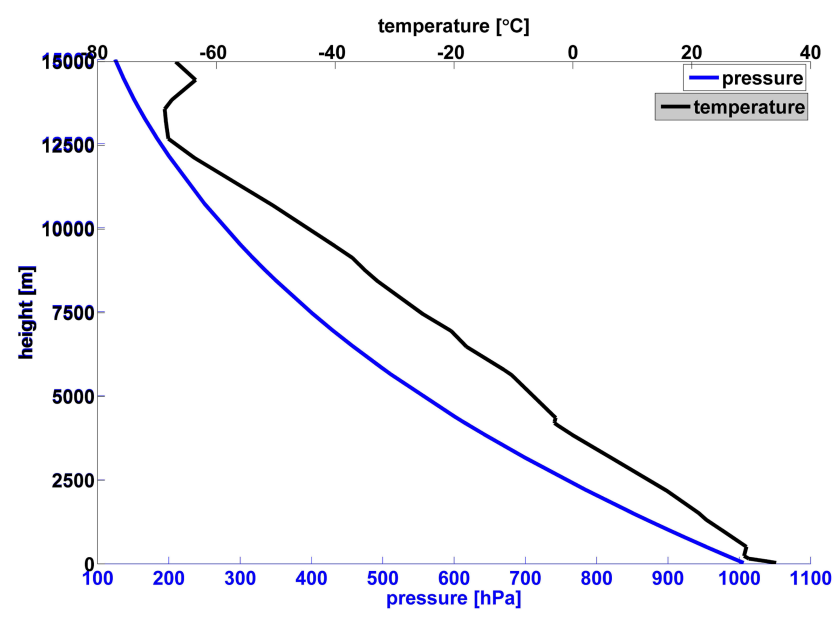

Fig. 12. The rasiosonde measured atmospheric temperature and pressure profile at the time of the FOV analysis.

\subsection{Free atmosphere clouds at nighttime}

A. Figure 13 presents the analysis of thermal images that were acquired by the SPECTATOR on 16 April 2010 at 00:50 GMT. Intersecting wind speeds indicates 4 possible cloud base heights: $950 \mathrm{~m}, 5310 \mathrm{~m}, 8350$, and $10300 \mathrm{~m}$. Analyzing the wind direction rules out all possible heights but $5310 \mathrm{~m}$, while according to the ceilometer sounding, at the time of the analysis the cloud base height was $5182 \mathrm{~m}$ ( $2.5 \%$ deviation).

B. Figure 14 presents the analysis of thermal images that were acquire by the SPECTATOR on 27 April 2010 at 20:50 GMT. Intersecting wind speeds indicate 3 possible cloud base heights: $962 \mathrm{~m}, 1045 \mathrm{~m}$, and $4720 \mathrm{~m}$. 

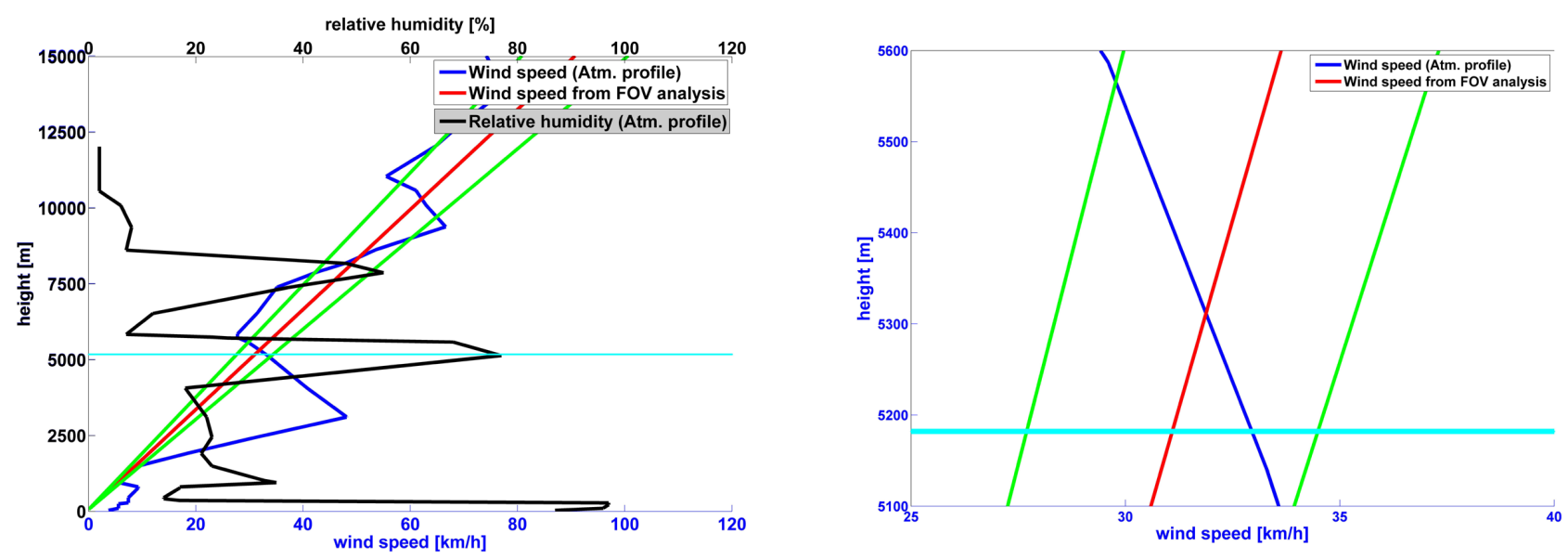

Fig. 13. Left: crossing measured wind velocity (blue line) with hypothesized possible wind velocities from FOV analysis (red line with green error lines). Notice the crossing points correspond to a high humidity layer (black line). Right: zooming in on the $5310 \mathrm{~m}$ crossing point. The cyan line is the cloud base height $(5182 \mathrm{~m})$ extracted by a nearby ceilometer (Website: "Station Observations").
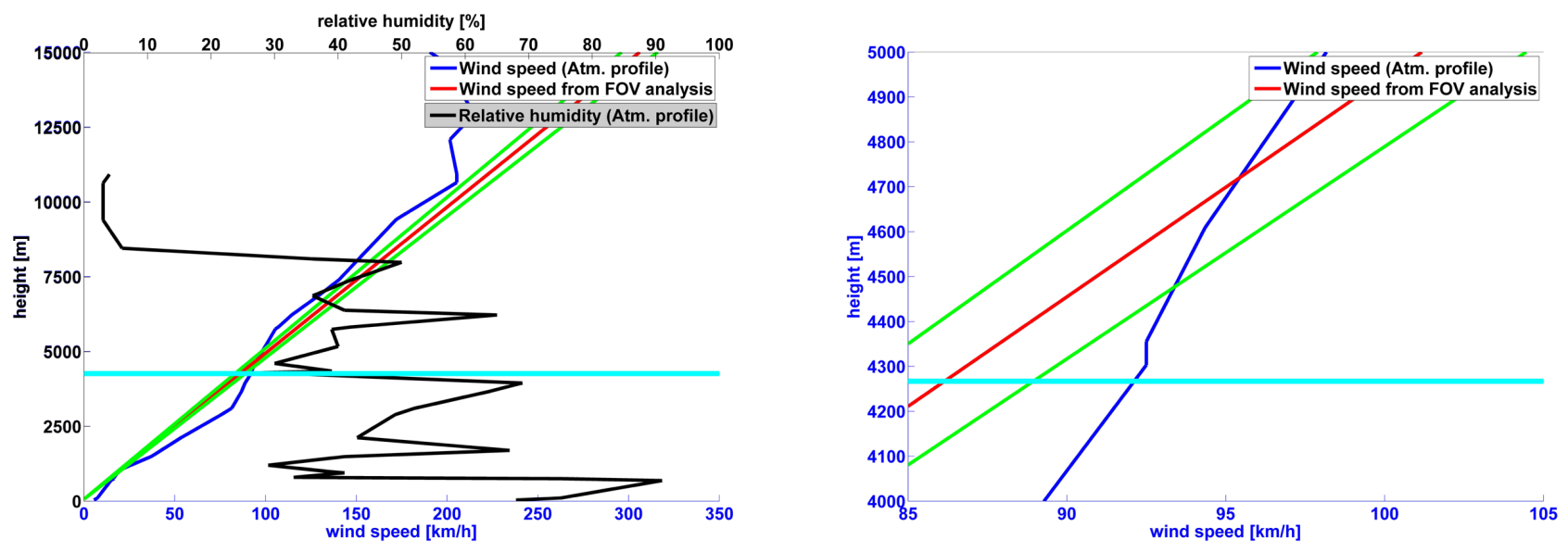

Fig. 14. Left: crossing measured wind velocity (blue line) with hypothesized possible wind velocities from FOV analysis (red line with green error lines). Right: zooming in on the $4720 \mathrm{~m}$ crossing point. The cyan line is the cloud base height ( $4267 \mathrm{~m})$ extracted by a nearby ceilometer (Website: "Station Observations").

Analyzing the wind direction rules out all possible heights but $4720 \mathrm{~m}$, while according to the ceilometer sounding, at the time of the analysis the cloud base height was $4267 \mathrm{~m}$ (10.6\% deviation).

\subsection{Continuous retrieval of clouds' base height}

In this subsection we provide 3 examples of obtained clouds' base height during $4 \mathrm{~h}$ of continuous operation. The utilization of the method is demonstrated for: low cumulus clouds field during daytime, high cirrus clouds during daytime, and multilayered cumulus and cirrus clouds during nighttime. The purpose of these examples is twofold. First, it enhances the confidence in the robustness and validity of the method and second, it enables to estimate the variance of the obtained clouds' base height.

\subsubsection{Shallow cumulus clouds field during daytime}

Figure 15 presents the clouds' base heights which were retrieved during 4 hours on 22 April 2010. The red line in the middle panel is the brightness temperature of the sky as measured in the centre of the field of view of the IR imager, and it is a sensitive proxy to cloud's presence exactly above the sensor, when the radiative temperature rises sharply. The Green circles on the top panel denotes the Ben-Gurion ceilometer's readings (Website: "Station Observations"), and the blue line is the extracted cloud base height. During that time, dense, shallow cumulus clouds field was present, as can be seen by examining the radiative temperature of the nadir sky (red line). The ceilometer's readings during these $4 \mathrm{~h}$ indicate an average cloud base of $1166 \mathrm{~m}$. Our method produced average cloud base height of $1602 \mathrm{~m}$ with a temporal standard 

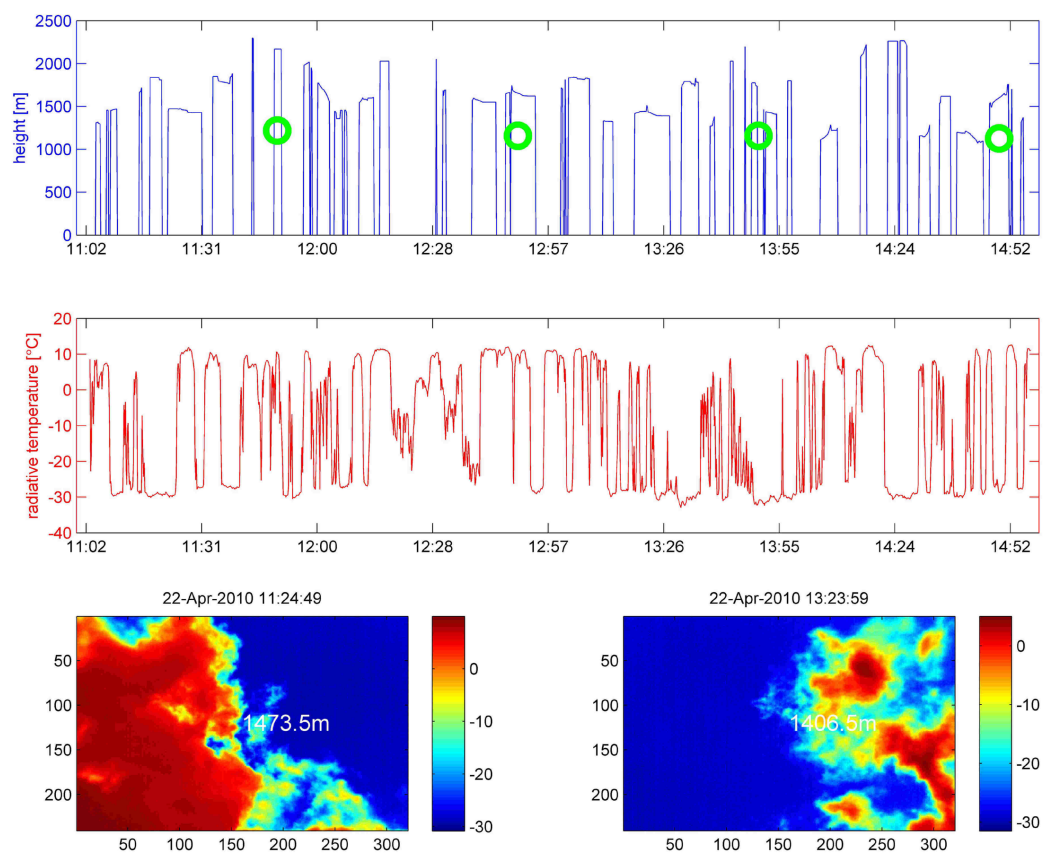

Fig. 15. Cloud base height as extracted by the proposed method during $4 \mathrm{~h}$ on 22 April 2010. Top panel: The blue line is the clouds base height as extracted by the proposed method and the green circles are the Ben-Gurion ceilometer readings (Website: "Station Observations"). The red line (middle panel) is the radiative temperature of the nadir sky as measured by the middle pixel of the IR imager. It provides a sensitive proxy for the presence of a cloud above our sensors, as the radiative temperature rises sharply. During that time, dense, shallow cumulus clouds field passed above the sensors. The method produced an average cloud base height of $1602 \mathrm{~m}$ with temporal standard deviation of $285 \mathrm{~m}$. The two images at the bottom of the figure are examples of specific clouds in that time frame that were extracted by the method.
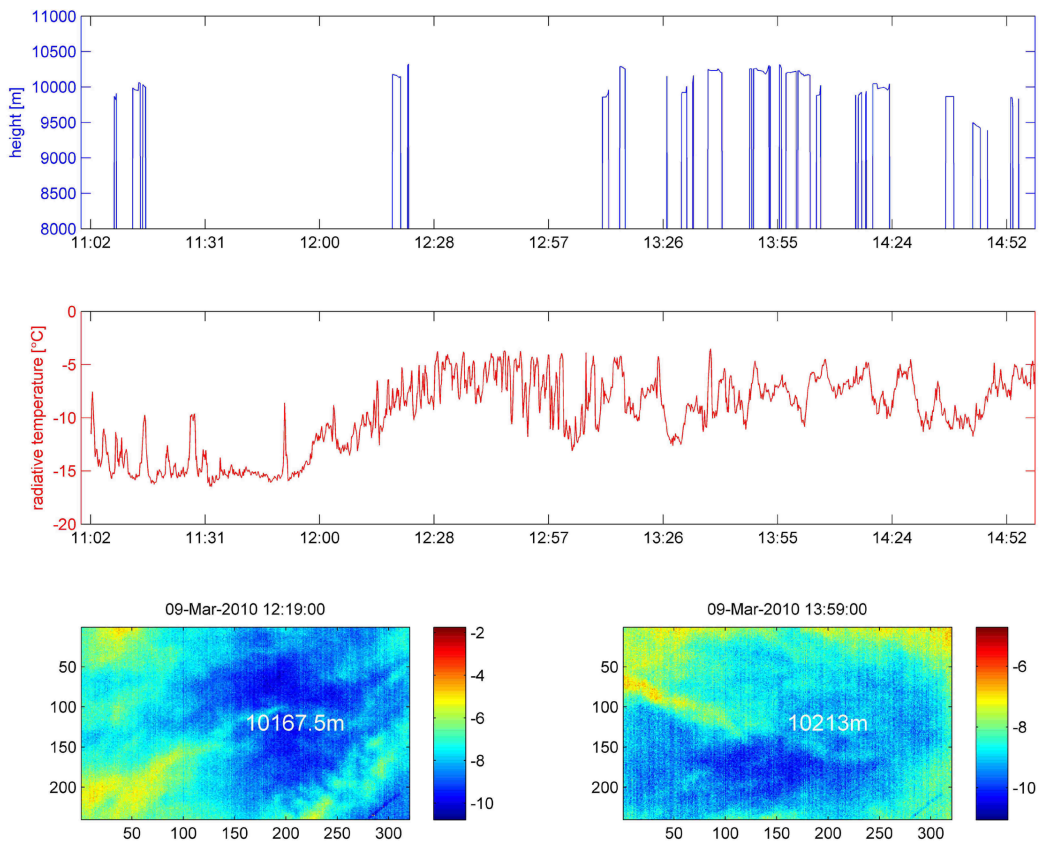

Fig. 16. Cloud base height as extracted by the proposed method during $4 \mathrm{~h}$ on 9 March 2010. The blue and red lines are as in Fig. 15. During that time, dense, high cirrus clouds field passed above the sensors. The method produced an average cloud base height of $10051 \mathrm{~m}$ with temporal standard deviation of $210 \mathrm{~m}$. The two images at the bottom of the figure are examples of specific clouds in that time frame that were extracted by the method. 

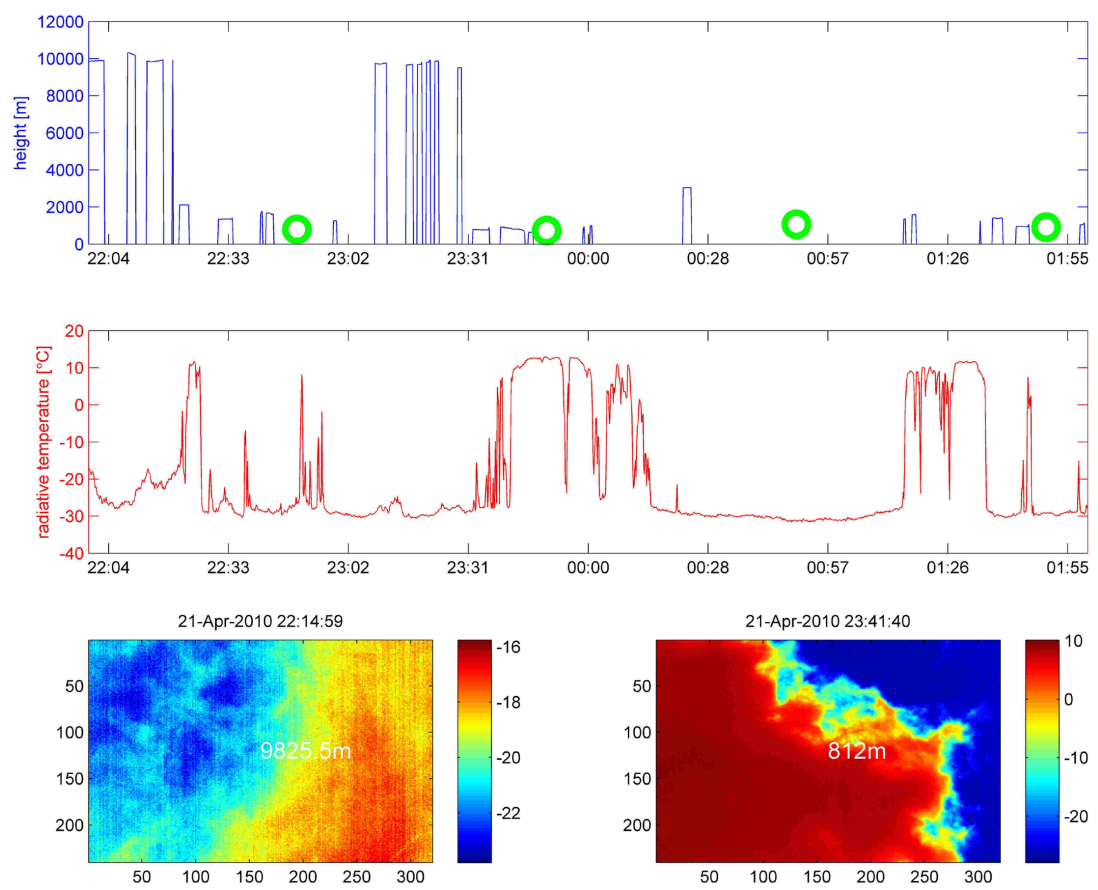

Fig. 17. Cloud base height as extracted by the proposed method during $4 \mathrm{~h}$ on the night of 21 April 2010. The blue and red lines are as in Fig. 15. During that time, multilayered sparse low cumulus and high cirrus clouds field passed above the sensors. The method successfully extracted the cloud base for both types as the sparse cumulus clouds enable to analyze the high cirrus clouds as well. The two images at the bottom of the Fig. 6 are examples of two distinct cloud types which were extracted during the above time frame.

deviation of $285 \mathrm{~m}$, considering only the times when valid cloud base heights (as described in Sect. 3.2) were obtained. Assuming there were no temporal fluctuations in the clouds' base height during that time and that the ceilometer provides their actual height, the proposed method overestimates the clouds height by $436 \mathrm{~m}$. This kind of over estimation is probably the result of imperfect representation of the boundary layer wind profile, as our method relies on the wind profile which is measured by a radiosonde from a meteorological station which is located approximately $8 \mathrm{~km}$ from our actual measurement site.

\subsubsection{High cirrus clouds field during daytime}

Figure 16 demonstrates the continuous operation of the method when dense, high cirrus clouds are present (as indicated by the increase and fluctuations in the sky radiative temperature). During the noon hours of 9 March 2010, an average cloud base height of $10051 \mathrm{~m}$ with standard deviation of $210 \mathrm{~m}$ was obtained. While we cannot validate the method's results during the complete $4 \mathrm{~h}$ period, the relatively low variability increases the confidence in the method's robustness.

\subsubsection{Multilayered cloud field during nighttime}

Figure 17 provides an example for the method's utility under multilayered clouds fields at nighttime. During $4 \mathrm{~h}$ in the night of 21 April 2010, sparse cumulus clouds passed above the sensor along with a high cirrus clouds field. The presence of these clouds is indicated by small fluctuations in the radiative temperature of the sky for the cirrus clouds (as noticed around 22:15 p.m. and 23:15 p.m.), and large fluctuations for the low cumulus clouds (as noticed at 00:00 a.m. and 01:30 a.m.). The sparse cumulus clouds field enabled the method to extract the upper layer height as well as the correct base height of the shallow clouds themselves, as validated by the ceilometer's readings (green circles).

\section{Conclusions}

We have presented a novel technique for deriving cloud base heights using thermal imaging from the ground combined with wind profile data. The method is based on calculating the angular velocity of the clouds and producing a hypothesized vertical wind profile. This profile is compared with the true (sounded) wind profile in the atmosphere, in order to derive the possible cloud base height. The method's main drawback is its need for updated wind profile, which can be obtained either by nearby radiosonde or by wind 
LIDAR. Another disadvantage is the theoretical possibility of retrieving ambiguous results where multiple cloud base heights might be produced. In spite the above, we have demonstrated the method's utility for low cumulus, free atmosphere, and high cirrus clouds, independent of cloud type or measurement hour. The method's utility was further tested on long time series and it was demonstrated the method produces robust and valid results even under multilayered clouds fields. Our obtained results were validated by using active sounding from the ground, atmospheric thermodynamic calculations (LCL), and passive space borne sounding. Since it is common to refer to active ceilometers readings as the "true" cloud base height (Craven, Jewell, \& Brooks, 2002), we suggest two possible explanations for the method's deviation from the ceilometer readings: (1) small spatial variations in the wind profile might result with different cloud base height. (2) The ceilometer reports the average value of all clouds passing over (usually within $0.5 \mathrm{~h}$ time period), while our method explores the height of a single cloud. The examples in the previous section demonstrate the method's efficiency in extracting clouds base height, with the usage of wind profile solely, while thermodynamic parameters such as LCL calculations are not relevant (clouds outside the boundary layer), or when standard ceilometers fail to detect them (high clouds). Further validation of this method should be made by quantitative performance analysis for different cloud types and measurement regions. Nevertheless, we believe this technique can be exploited as complementary analysis to space-borne passive remote sensing, or integrated with commercial whole sky imagers to analyze both the fractional cloud coverage and base height as well. The proposed method can expand the capability of cloud field sounding both in space and time. In addition, it might be particularly useful at field campaigns or at remote locations due to its simplicity and low power consumption needs. The equipment needed for this method is simple and relatively inexpensive and can be further simplified by using a visible camera instead of a thermal imager (although nighttime clouds would then not be observable).

Acknowledgements. The authors are thankful to Amnon Sharon for his essential technical support in establishing and maintaining the measurement assembly. This research was supported by the Israel Science Foundation (grant 1172/10) and the Minerva Foundation (grant 780048).

Edited by: B. Mayer

\section{References}

AERONET Data Display - Site: Nes_Ziona: Retrieved from http: //aeronet.gsfc.nasa.gov/cgi-bin/type_one_station_opera_v2_new? site $=$ Nes $Z$ Ziona \&nachal $=2 \&$ level $=3 \&$ place $\_$code $=10$, last access: 17 May, 2010.

Atmospheric Sounding: Retrieved from http://weather.uwyo.edu/ upperair/sounding.html, last access: March-May, 2010.

Bolton, D.: The computation of equivalent potential temperature, Mon. Weather Rev., 108, 1046-1053, 1980.

Chernykh, I. V. and Eskridge, R. E.: Determination of cloud amount and level from radiosonde sounding, J. Appl. Meteorol., 35, 1362-1369, 1996.

Chiu, J. C., Marshak, A., Wiscombe, W. J., Valencia, S., and Welton, E. J.: Cloud Optical Depth Retrievals from Solar Background Signal of Micropulse Lidars, Geosci. Remote Sens. Lett., 43, 456-460, 2007.

Craven, J. P., Jewell, R. E., and Brooks, H. E.: Comparison between observed convective cloud-base heights and lifting condesation level for two different lifted air parcels, Weather Forecast., 17, 885-890, 2002.

Deardorff, J. W.: Parameterization of the planetary boundary layer for use in general ciculation models, Mon. Weather Rev., 100, 93-106, 1972.

Fujita, T., Bradbury, D. L., Murino, C., and Mull, L.: A study of mesoscale cloud motions computed from ATS-1 and terrestrial photographs from satellite, Mesometeorological Research Project Research Paper No. 71, Dept. of Geophysical Sciences, Univ. of Chicago, Chicago, p. 25, 1968.

Holben, B. N., Eck, T. F., Slutsker, I., Tanre, D., Buis, J. P., Setzer, A., Vermote, E., Reagan, J. A., Kaufman, Y. J., Nakajima, T., Lavenu, F., Jankowiak, I., and Smirnov, A.: AERONET - A federated instrument network and ata archive for aerosol characterization, Remote Sens. Environ., 66, 1-16, 1998.

Horváth, Á. and Davies, R.: Feasibility and Error Analysis of Cloud Motion Wind Extraction from Near-Simultaneous Multiangle MISR Measurements, J. Atmos. Ocean. Tech., 18, 591608, 2001.

IPCC: Climate Change 2007: The Physical Science Basis, Contribution of Working Group I to the Fourth Assessment Report of the Intergovernmental Panel on Climate Change, edited by: Solomon, S., Qin, D., Manning, M., Chen, Z., Marquis, M., Averyt, K. B., Tignor, M. and Miller, H. L., Cambridge University Press, Cambridge, UK and New York, NY, USA, 995 pp., 2007.

Jahne, B.: Digital Image Processing, 4th edition, Springer-Verlag, Berlin, Heidelberg, Germany, p. 555, 1997.

Kambhamettu, C., Palaniappan, K., and Hasler, A. F.: Automated cloud-drift winds from GOES images, Proc. SPIE GOES-8 and Beyond, 122-133, 1996.

Kiehl, J. T. and Trenberth, K. E.: Earth's Annual Global Mean Energy Budget, B. Am. Meteorol. Soc., 78, 197-208, 1997.

Koren, I., Remer, L. A., Altaratz, O., Martins, J. V., and Davidi, A.: Aerosol-induced changes of convective cloud anvils produce strong climate warming, Atmos. Chem. Phys., 10, 5001-5010, doi:10.5194/acp-10-5001-2010, 2010.

Kummerow, C., Barnes, W., Kozu, T., Shiue, J., and Simpson, J.: The Tropical Rainfal Measuring Mission (TRMM) Sensor Package, J. Atmos. Ocean. Tech., 15, 809-817, 1998.

LAADS Web: Retrieved from http://ladsweb.nascom.nasa.gov/, last access: March-May, 2010. 
Leese, J. A., Novak, C. S., and Clark, B. B.: An automated technique for obtaining cloud motion from geosynchronous satellite data using cross-correlation, J. Appl. Meteorol., 10, 118-132, 1971.

Long, C. N., Slater, D. W., and Tooman, T.: Total Sky Imager Model 880 Status and Testing Results, retrieved from http:// www.arm.gov/publications/tech_reports/arm-tr-006.pdf, last access: 2 June 2010, 2001.

Mahesh, A., Walden, V. P., and Warren, S. G.: Ground-Based infrared remote sensing of cloud properties over the Antarctic Plateau, Part I: Cloud base heights, J. Appl. Meteorol., 40, 12651278, 2001.

Naud, C., Muller, J. P., and Clothiaux, E. E.: Comparison between active sensor and radiosonde cloud boundaries over the ARM southern Great Plains site, J. Geophys. Res., 108, 4140, 2003.

Ottenbacher, A., Tomassini, M., Holmlund, K., and Schmetz, J.: Low-Level Cloud Motion Winds from Meteosat High-Resolution Visible Imagery, Weather Forecast., 12, 175-184, 1997.

Pal, S. R., Steinbrecht, W., and Carswell, A. I.: Autmated method for lidar detemination of cloud-base height and vertical extent, Appl. Optics, 31, 1488-1494, 1992.

Platnick, S., King, M. D., Ackerman, S. A., Menzel, W. P., Baum, B. A., Ri'edi, J. C., and Frey, R. A.: The MODIS cloud products: algorithm and examples from Terra, IEEE T. Geosci.Remote, 41(2), 459-473, 2003.

Schafer, K., Emeis, S. M., Rauch, A., Munkel, C., and Vogt, S.: Determination of mixing layer heights from ceilometer data, Proc SPIE, 5571, 248, doi:10.1117/12.565592, 2004.

Schmetz, J., Holmlund, K., Hoffman, J., Strauss, B., Mason, B., Gaertner, V., Koch, A., and Van de Berg, L.: Operational cloudmotion winds from Meteosat infrared images, J. Appl. Meteorol., 32, 1206-1225, 1993.
Schmetz, J., Pili, P., Tjemkes, S., Just, D., Kerkmann, J., Rota, S., and Ratier, A.: An introduction to Meteosat Second Generation (MSG), B. Am. Meteorol. Soc., 83, 977-992, 2002.

Schreiner, A. J. and Menzel, P.: Comparison of cloud motion vector height assignment techniques using GOES-12 imager, Sixth International Winds Workshop, Madison Wisconsin, USA, EUMETSAT, EUM P35, 301-305, 2002.

Station Observations: Retrieved from http://weather.uwyo.edu/ surface/meteogram/, last access: March-May, 2010.

Stephens, G. L., Vane, D. G., Boain, R. J., Mace, G. G., Sassen, K., Wang, Z., Illingworth, A. J., O’Connor, E. J., Rossow, W. G., Durden, S. L., Miller, S. D., Austin, R. T., Benedetti, A., and Mitrescu, C.: The cloudsat mission and the A-train, B. Am. Meteorol. Soc., 83, 1771-1790, 2002.

Tan, D. and Andersson, E.: Simulation of the yield and accuracy of wind profile measurements from the Atmospheric Dynamics Mission (ADM-Aeolus), Q. J. Roy. Meteorol. Soc., 131, 17371757, 2005.

Velden, S. V., Hayden, C. M., Nieman, S. J., Menzel, W. P., Wanzong, S., and Goerss, J. S.: Upper-tropospheric winds derived from geostationary satellite water vapor observations, B. Am. Meteorol. Soc., 78, 173-195, 1997.

Wang, J. and Rossow, W. B.: Determination of Cloud Vertical Structure from Upper-Air Observations, J. Appl. Meteorol., 34, 2243-2258, doi:10.1175/1520-0450, 1995.

Winker, D. M., Pelon, J. R., and McCormick, M. P.: The CALIPSO mission: spaceborne lidar for observations of aerosols and clouds, Proc. SPIE, 4893, 1-11, 2003. 